\title{
Post-EBV Cerebellitis: A Very Rare Complication of Infectious Mononucleosis
}

\author{
Muddasir Ashraf
}

\begin{abstract}
Post-Epstein-Barr virus (EBV) cerebellitis is a very rare complication of infectious mononucleosis. It is almost always seen before 6 years of age and very few adult cases are reported in literature. We present a 21-year-old patient with post-EBV cerebellitis who presented with ataxia and slurred speech 2 weeks after infectious mononucleosis. The patient had a positive monospot test and positive EB viral capsid IgM and IgG, and negative Epstein-Barr nuclear antigen IgG which is consistent with recent infection. The patient's brain imaging and CSF evaluation were normal. His symptoms resolved almost completely after 3 - 4 weeks.
\end{abstract}

Keywords: EBV; Cerebellitis; Ataxia

\section{Introduction}

Post-infectious cerebellitis/acute cerebellar ataxia has been reported in literature in children less than 6 years of age and it is very rare after Epstein-Barr virus (EBV) infection, especially in children greater than 15 [1-3]. We present another interesting case of post-EBV cerebellitis in a 21-year-old patient with confirmed infectious mononucleosis.

\section{Case Report}

This is a 21-year-old white American male who presented to an urgent care clinic with symptoms of lymph node swelling for which he was prescribed antibiotics. A week later, he developed fever and severe sore throat for which he was continued on antibiotics and prescribed oral lidocaine. Next

\footnotetext{
Manuscript accepted for publication April 11, 2014

Hospital Medicine, Trinity Medical Center, Rock Island, IL 61201, USA. Email: muddasirashraf@hotmail.com

doi: http://dx.doi.org/10.14740/jmc1779w
}

day he developed rash and ended up going back to the urgent care clinic where he was prescribed prednisone and tested for infectious mononucleosis with a monospot test which came back positive. His rash resolved, but the patient developed gait ataxia and slurred speech 3 days later which did not resolve over the next 3 - 4 days and the patient presented to our emergency department for further evaluation. The patient denied any history of head trauma and also any history of drug abuse or alcohol abuse. His physical exam revealed pertinent findings of severe gait as well as both upper and lower limb ataxia. Right lower extremity ataxia was more than left lower extremity ataxia. The patient also had right lateral gaze nystagmus. Labs revealed positive EBV viral capsid IgM and IgG, but his Epstein-Barr nuclear antigen IgG was negative, consistent with recent infection. Liver function tests showed ALT of 405, AST of 97 and alkaline phosphatase of 156 which improved during the hospital course. Urine toxicology screen and alcohol levels were normal. The patient had CT and MRI brain done which were completely normal. CSF evaluation was unremarkable including negative EBV and herpes simplex virus PCR. He was finally diagnosed with post-EBV cerebellitis. Patient was discharged to inpatient rehabilitation unit and he improved remarkably over the period of $3-4$ weeks which is the natural course of this disease.

\section{Discussion}

Post-infectious cerebellitis has been observed following many infectious diseases, including varicella, EBV, roseola (human herpes virus 6), enterovirus, rubeola, parvovirus and mycoplasma infection $[1,2,4-8]$. It is characterized by the symptoms of slurred speech, ataxia and nystagmus. It usually occurs after the acute EBV infection which suggests autoimmune nature of the disease rather than direct EBV infection itself. Antiviral antibodies and autoreactive antibodies against Purkinje cells, centrosomes and myelin-associated glycoprotein have been isolated from cerebrospinal fluid in some affected patients $[1,6,9,10]$ which again supports the possible autoimmune etiology. However, in other case reports, viral nucleic acids have been identified in the cere- 
brospinal fluid, suggesting that infection of brain tissue may contribute to the disorder [2]. CSF studies are often normal in such patients though, including the negative PCR. MRI is typically normal in most cases at the time of symptoms but may show abnormalities in cerebellar enhancement if done at early stages before neurological symptoms develop. It is usually done to rule out other causes. It is differentiated from viral labyrinthitis by the fact that you don't see slurred speech and limb ataxia in labyrinthitis. History of head trauma should also be ruled out. The work-up should include urine toxicology screen and alcohol level to rule out any toxic causes. Symptoms improve remarkably over the course of 2 - 3 weeks $[1,2]$ which was the case in our patient.

\section{Conclusion}

We should always remember that sometimes diseases know no age boundaries. It will help us stop misdiagnosing such patients and labeling them incorrectly with poor prognosis.

\section{Disclosure}

No conflict of interest exists.

\section{References}

1. Connolly AM, Dodson WE, Prensky AL, Rust RS. Course and outcome of acute cerebellar ataxia. Ann
Neurol. 1994;35(6):673-679.

2. Nussinovitch M, Prais D, Volovitz B, Shapiro R, Amir J. Post-infectious acute cerebellar ataxia in children. Clin Pediatr (Phila). 2003;42(7):581-584.

3. Weiss, S, Carter, S. Course and prognosis of acute cerebellar ataxia in childhood. Neurology. 1959;9:711.

4. Guess HA, Broughton DD, Melton LJ 3rd, Kurland LT. Population-based studies of varicella complications. Pediatrics. 1986;78:723.

5. Ito H, Sayama S, Irie S, Kanazawa N, Saito T, Kowa H, Haga $\mathrm{S}$, et al. Antineuronal antibodies in acute cerebellar ataxia following Epstein-Barr virus infection. Neurology. 1994;44(8):1506-1507.

6. Cohen HA, Ashkenazi A, Nussinovitch M, Amir J, Hart J, Frydman M. Mumps-associated acute cerebellar ataxia. Am J Dis Child. 1992;146(8):930-931.

7. Shimizu Y, Ueno T, Komatsu H, Takada H, Nunoue T. Acute cerebellar ataxia with human parvovirus B19 infection. Arch Dis Child. 1999;80(1):72-73.

8. Hata A, Fujita M, Morishima T, Kumakura A, Hata D. Acute cerebellar ataxia associated with primary human herpesvirus-6 infection: a report of two cases. J Paediatr Child Health. 2008;44(10):607-609.

9. Davis DP, Marino A. Acute cerebellar ataxia in a toddler: case report and literature review. J Emerg Med. 2003;24(3):281-284.

10. Shiihara T, Kato M, Konno A, Takahashi Y, Hayasaka K. Acute cerebellar ataxia and consecutive cerebellitis produced by glutamate receptor delta2 autoantibody. Brain Dev. 2007;29(4):254-256. 